\title{
THE EFFICACY AND SAFETY OF SORAFENIB TREATMENT ON METASTATIC DIFFERENTIATED THYROID CARCINOMAS
}

\author{
PInar SISMAN", Mustafa SUVERAN ${ }^{2}$, Ahmet Bilgehan SAHIN², Soner CANDER \\ Ozen OZ GUL ${ }^{1}$, Erdinc ERTURK' ${ }^{1}$, Canan ERSOY ${ }^{1}$
}

Uludag University, Faculty of Medicine, Department of Endocrinology and Metabolism, Bursa, Turkey ${ }^{1}$

Uludag University, Faculty of Medicine, Department of Internal Medicine, Bursa, Turkey ${ }^{2}$

\section{INTRODUCTION}

Differentiated thyroid carcinomas (DTC) are originated from thyroid follicular epithelial cells and comprises \%90 of all thyroid carcinomas.

Researches indicate that sorafenib is more efficacious than other chemotherapeutic agents on metastatic iodide refractory DTCs.

\section{MATERIAL AND METHODS}

In our center, between 2013 and 2015, sorafenib was applied to 6 patients who had iodide refractory metastatic DTC. Five of the patients were female.

The mean age at diagnosis was 68.6. Minimum 150, maximum $800 \mathrm{mCi}$ RAl treatment were administered to the patients were applied after total

thyroidectomy.

\section{RESULTS}

After sorafenib treatment, on the follow-up skin rashes were the most frequent adverse effect and followed by hypertension, high ventricular rate atrial fibrillation and esophagitis. Skin lesions were mild and occurred on the first month of the treatment, after dose reduction symptoms resolved by 1 month. One patient had died of pericardial effusion (Table1). The response rates were evaluated according to "response evaluation criteria in solid tumors RECIST". Progressive disease, stable disease, and partial response were observed in 3 patients, one patient and one patient, respectively. One patient has not been assessed by imaging.

\section{DISCUSSION}

Literature indicates that the adverse effects occur at the early phase, after reducing the dose or quitting, symptoms resolve and by the time patients' drug tolerance increase. Younger patients' drug compliance is higher. In our patients, adverse effects occurred in the first month consistent with literature. After dose reduction and treatment of the adverse effects, all of the symptoms resolved. However, low drug tolerance was observed in our patients and attributed to the advanced ages of the patients.

\section{CONCLUSION}

The efficacy of sorafenib is higher than the conventional chemotherapeutics, but management of side effects is crucial. Therefore, the patients should be informed about side effects before treatment and it should be used in experienced centers.

Table1: Side effects after sorafenib treatment

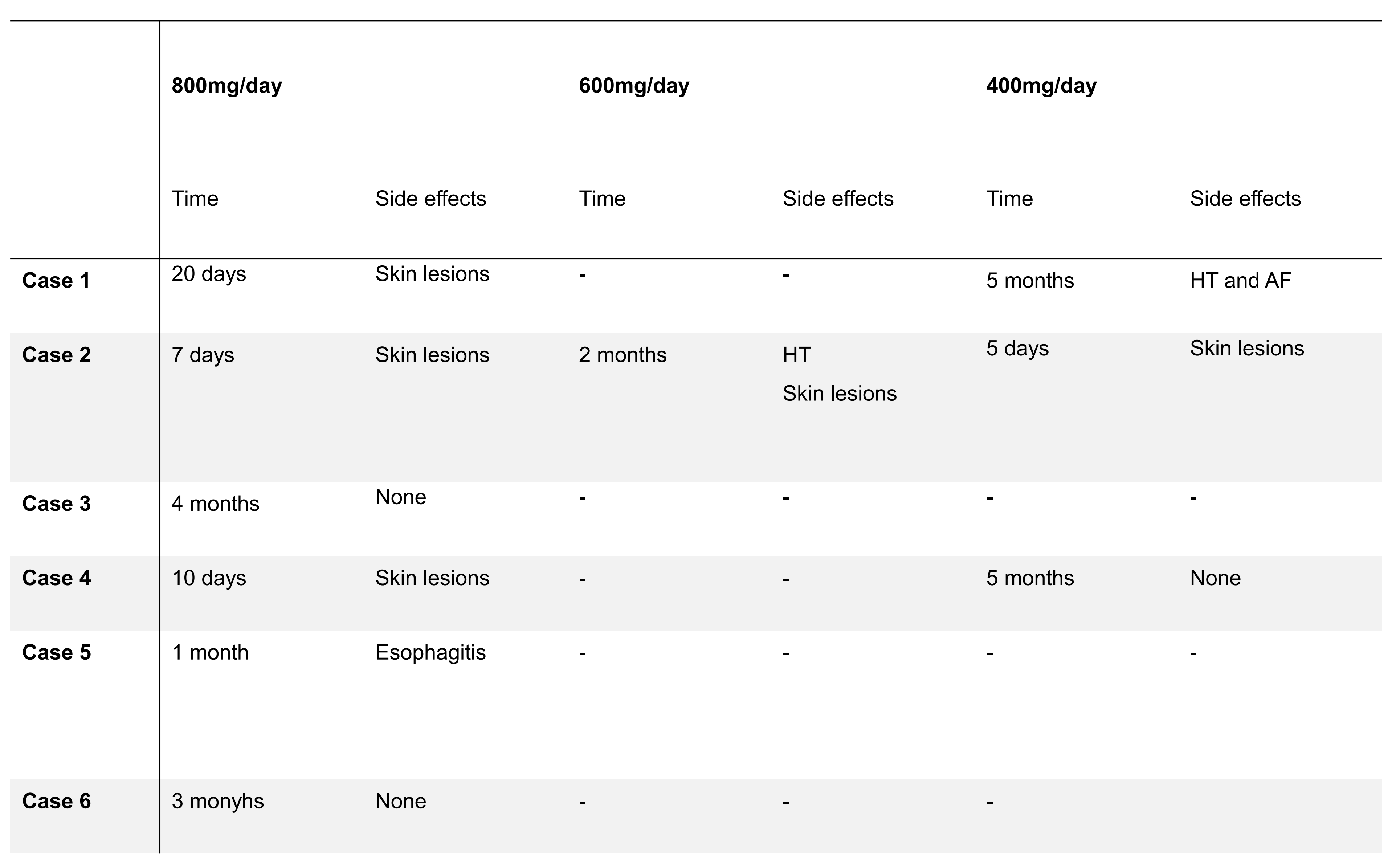

